\title{
ONREL
}
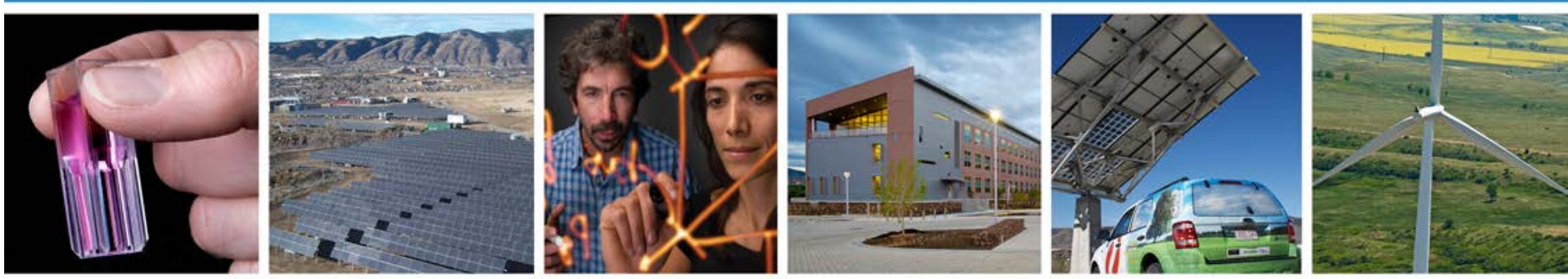

\section{Light Trapping for Thin Silicon Solar Cells by Femtosecond Laser Texturing}

\section{Preprint}

Benjamin G. Lee and Howard M. Branz National Renewable Energy Laboratory

Yu-Ting Lin, Eric Mazur, and Meng-Ju Sher Harvard University

Presented at the 2012 IEEE Photovoltaic Specialists Conference Austin, Texas

June 3-8, 2012

NREL is a national laboratory of the U.S. Department of Energy, Office of Energy Efficiency \& Renewable Energy, operated by the Alliance for Sustainable Energy, LLC.

Conference Paper

NREL/CP-5200-54122

June 2012

Contract No. DE-AC36-08GO28308 


\section{NOTICE}

The submitted manuscript has been offered by an employee of the Alliance for Sustainable Energy, LLC (Alliance), a contractor of the US Government under Contract No. DE-AC36-08GO28308. Accordingly, the US Government and Alliance retain a nonexclusive royalty-free license to publish or reproduce the published form of this contribution, or allow others to do so, for US Government purposes.

This report was prepared as an account of work sponsored by an agency of the United States government. Neither the United States government nor any agency thereof, nor any of their employees, makes any warranty, express or implied, or assumes any legal liability or responsibility for the accuracy, completeness, or usefulness of any information, apparatus, product, or process disclosed, or represents that its use would not infringe privately owned rights. Reference herein to any specific commercial product, process, or service by trade name, trademark, manufacturer, or otherwise does not necessarily constitute or imply its endorsement, recommendation, or favoring by the United States government or any agency thereof. The views and opinions of authors expressed herein do not necessarily state or reflect those of the United States government or any agency thereof.

Available electronically at http://www.osti.gov/bridge

Available for a processing fee to U.S. Department of Energy and its contractors, in paper, from:

U.S. Department of Energy

Office of Scientific and Technical Information

P.O. Box 62

Oak Ridge, TN 37831-0062

phone: 865.576.8401

fax: 865.576 .5728

email: mailto:reports@adonis.osti.gov

Available for sale to the public, in paper, from:

U.S. Department of Commerce

National Technical Information Service

5285 Port Royal Road

Springfield, VA 22161

phone: 800.553 .6847

fax: 703.605.6900

email: orders@ntis.fedworld.gov

online ordering: http://www.ntis.gov/help/ordermethods.aspx

Cover Photos: (left to right) PIX 16416, PIX 17423, PIX 16560, PIX 17613, PIX 17436, PIX 17721

Printed on paper containing at least $50 \%$ wastepaper, including $10 \%$ post consumer waste. 


\title{
Light Trapping for Thin Silicon Solar Cells by Femtosecond Laser Texturing
}

\author{
Benjamin G Lee ${ }^{1}$, Yu-Ting Lin ${ }^{2}$, Meng-Ju Sher ${ }^{3}$, Eric Mazur ${ }^{2,3}$, Howard M. Branz ${ }^{1}$ \\ ${ }^{1}$ National Center for Photovoltaics, National Renewable Energy Laboratory, Golden CO 80401 USA \\ ${ }^{2}$ School of Engineering and Applied Sciences, Harvard University, Cambridge, MA 02138 USA \\ ${ }^{3}$ Department of Physics, Harvard University, Cambridge, MA 02138 USA
}

\begin{abstract}
Femtosecond laser texturing is used to create nano- to micron-scale surface roughness that strongly enhances light-trapping in thin crystalline silicon solar cells. Light trapping is crucial for thin solar cells where a single light-pass through the absorber is insufficient to capture the weakly absorbed red and near-infrared photons, especially with an indirect-gap semiconductor absorber layer such as crystalline $\mathrm{Si}$ which is less than $20 \mu \mathrm{m}$ thick [1-2]. We achieve enhancement of the optical absorption from light-trapping that approaches the Yablonovitch limit [3].
\end{abstract}

Index Terms - light trapping, laser texturing, epitaxial silicon, femtosecond laser, Lambertian.

\section{INTRODUCTION}

The development of epitaxial, thin, crystalline Si solar cells has the goal of approaching the high efficiency of wafer-based $\mathrm{Si}$ cells, while using only a fraction as much $\mathrm{Si}$ [1-2]. The expectation is that these thin silicon cells will have dramatically lower production costs, and good potential for scalability to large areas. A key challenge for these $\sim 2-20 \mu \mathrm{m}$ thick cells is achieving sufficient photocurrent, which can be improved by capturing more of the weakly absorbed red and near-infrared incident sunlight.

Light trapping can increase the path-length of light, using total internal reflection to keep light inside the cell. A cell with a randomly textured surface giving Lambertian lightscattering can theoretically achieve the Yablonovitch lighttrapping limit [3]. For weakly-absorbed light, the Yablonovitch path-length enhancement factor is $4 \mathrm{n}^{2} \sim 50 \mathrm{x}$ in $\mathrm{Si}(\mathrm{n} \sim 3.5)$ for infrared photons near the bandedge.

$\mathrm{KOH}$ etching is a proven, industrial method of texturing $\mathrm{Si}$; it produces random pyramids that can enhance light-trapping to near the Yablonovitch limit [4]. However, $\mathrm{KOH}$ etching typically removes many microns of $\mathrm{Si}$, which may not be economical for thin silicon cells. Moreover, it only works well on (100) oriented Si.

Two alternative methods are texturing $\mathrm{Si}$ with plasma etching [5] or laser pulses. Here, we demonstrate the potential of femtosecond laser pulses for creating a nearly ideal random texture on $\mathrm{Si}$; our laser texture can greatly enhance lighttrapping while simultaneously decreasing reflectivity.

\section{FEMTOSECOND LASER TEXTURING}

A variety of surface morphologies can be obtained from fs laser treatments, depending on laser parameters and the ambient gas environment [6-7]. We target wavelength-scale and larger features to: a) reduce reflectivity by directing reflected light to neighboring valley walls; and b) scatter light at large angles, resulting in light-trapping due to total internal reflection.
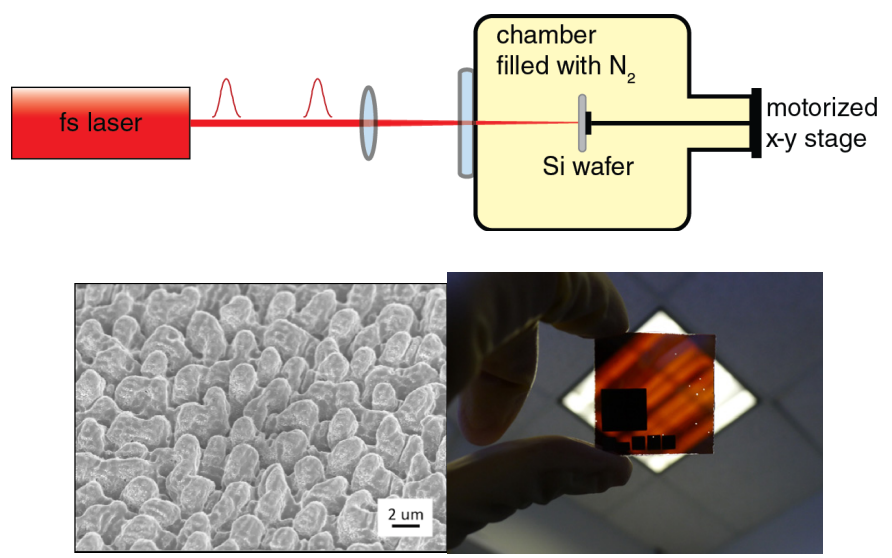

Fig. 1. (a) Schematic of femtosecond laser texturing apparatus. (b) SEM image of laser textured Si. (c) Thin $(\sim 2 \mu \mathrm{m})$ crystalline Si film on glass. Dark areas have been laser-textured.

We scan fs-laser pulses over the surface of a Si sample, with the sample located inside a vacuum chamber with motorized stage (Fig. 1a). Each fs laser pulse locally melts Si at the surface, which rapidly resolidifies. Optical interference effects cause rippling in the re-formed Si surface. Successive irradiation with laser pulses causes these instabilities to grow into "hills and valleys." Importantly, this change in morphology happens with negligible loss of material from ablation.

Texturing was done in $\mathrm{N}_{2}$ gas ambient, with $4 \mathrm{~kJ} / \mathrm{m}^{2}$ laser fluence, 800 shots/area and $800 \mathrm{~nm}$ center wavelength. We generated $\sim 0.1-1 \mu \mathrm{m}$ scale features with a large degree of random roughness (Fig. 1b). The laser texturing dramatically modifies the optical properties of thin Si films. In Fig. 1c, we see that while untextured $2-\mu \mathrm{m}$-thick crystalline $\mathrm{Si}$ is mostly 
transparent, the textured areas are opaque due to the enhanced absorption by light-trapping.

\section{OPTICAL PROPERTIES}

We investigate the absorption of laser-textured $\mathrm{Si}$ quantitatively, in order to determine the benefit of texturing to both light-trapping and also reduced reflectivity. Optical transmission and reflection measurements were performed using a Varian Cary 6000i spectrophotometer, equipped with an integrating sphere to collect diffusely transmitted/reflected light. The absorption was calculated by $\mathrm{A}=1-\mathrm{T}-\mathrm{R}$.

The absorption of both 400 and $20 \mu \mathrm{m}$ thick Si wafers show similar behavior (Fig. 2). The texture decreases reflectivity across the spectrum. This is its primary benefit at shorter wavelengths, $<1000 \mathrm{~nm}$ and $<800 \mathrm{~nm}$ respectively for the 400 and $20 \mu \mathrm{m}$ thick wafers. The reduction in reflectivity, as compared to a flat wafer, is nearly as good as a $75 \mathrm{~nm}$ silicon nitride AR coating $(\mathrm{n} \sim 2)$.
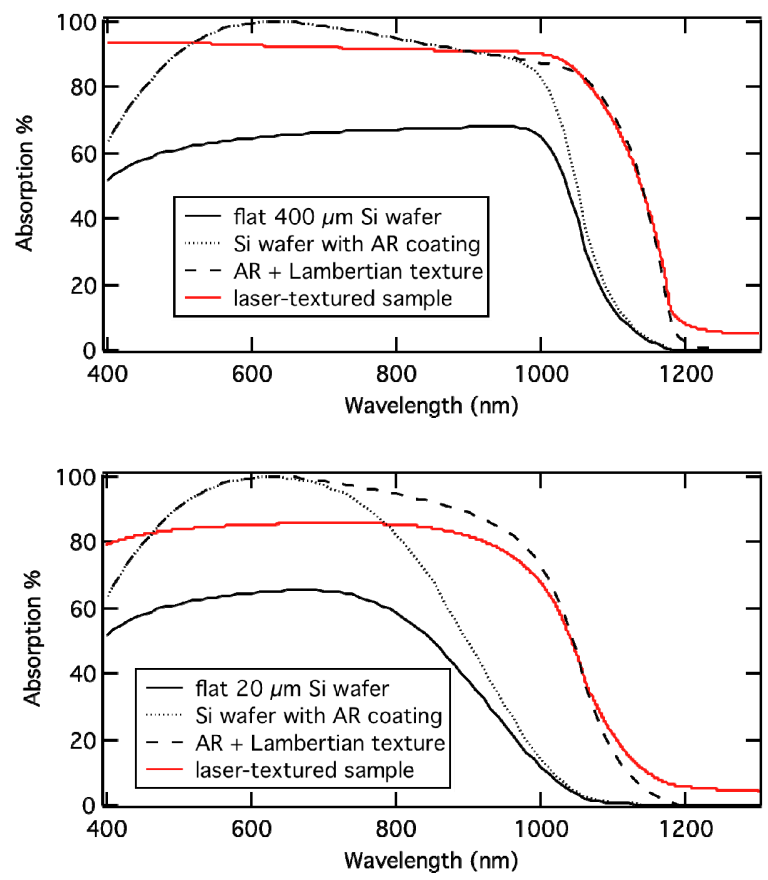

Fig. 2. Optical absorption of (a) $400 \mu \mathrm{m}$ and (b) $20 \mu \mathrm{m}$ thick Si wafers with laser-textured front side, as compared to theoretical absorption spectra for a flat wafer, a flat wafer with silicon nitride AR coating, and with Lambertian (Yablonovitch) light trapping.

The laser texture also significantly enhances the lighttrapping in the long-wavelength region, $>1000 \mathrm{~nm}$ and $>800$ $\mathrm{nm}$ respectively for the 400 and $20 \mu \mathrm{m}$ thick wafers. This is particularly evident for the thinner $20 \mu \mathrm{m}$ wafer (Fig. 2b). In both cases, the absorption enhancement is practically at the Yablonovitch light-trapping limit. We attribute this excellent light-trapping to the nearly ideal random texture created by fs laser treatment.

\section{TEXTURED SOLAR CELL}

To demonstrate the efficacy of fs laser texturing for solar cell devices, we study texturing of a thin, epitaxial crystalline $\mathrm{Si}$ cell. The $\mathrm{Si}$ was deposited by hot-wire chemical vapor deposition (HWCVD) hetero-epitaxial growth on a sapphire substrate [8]. First, a heavily n-doped bottom contact was grown $2 \mu \mathrm{m}$ thick (Fig. 3a). Then, the $4-\mu \mathrm{m}$-thick lightly ndoped absorber layer was grown.

Subsequently, the surface of the epitaxial Si film was lasertextured. After laser-texturing, we performed various chemical cleaning steps. We are investigating the benefit of a wet chemical etch that can remove some thickness of Si which is damaged in the laser process. The cell junction is formed by depositing $\sim 6 \mathrm{~nm}$ intrinsic and $15 \mathrm{~nm}$ p-doped amorphous $\mathrm{Si}$, giving a Si heterojunction emitter. $75 \mathrm{~nm}$ indium tin oxide (ITO) is deposited as a top contact. A $0.05 \mathrm{~cm}^{2}$ mesa cell was isolated by etching down to the highly-doped bottom contact. Light enters the cell through the top side and a silver back mirror is used at the bottom.

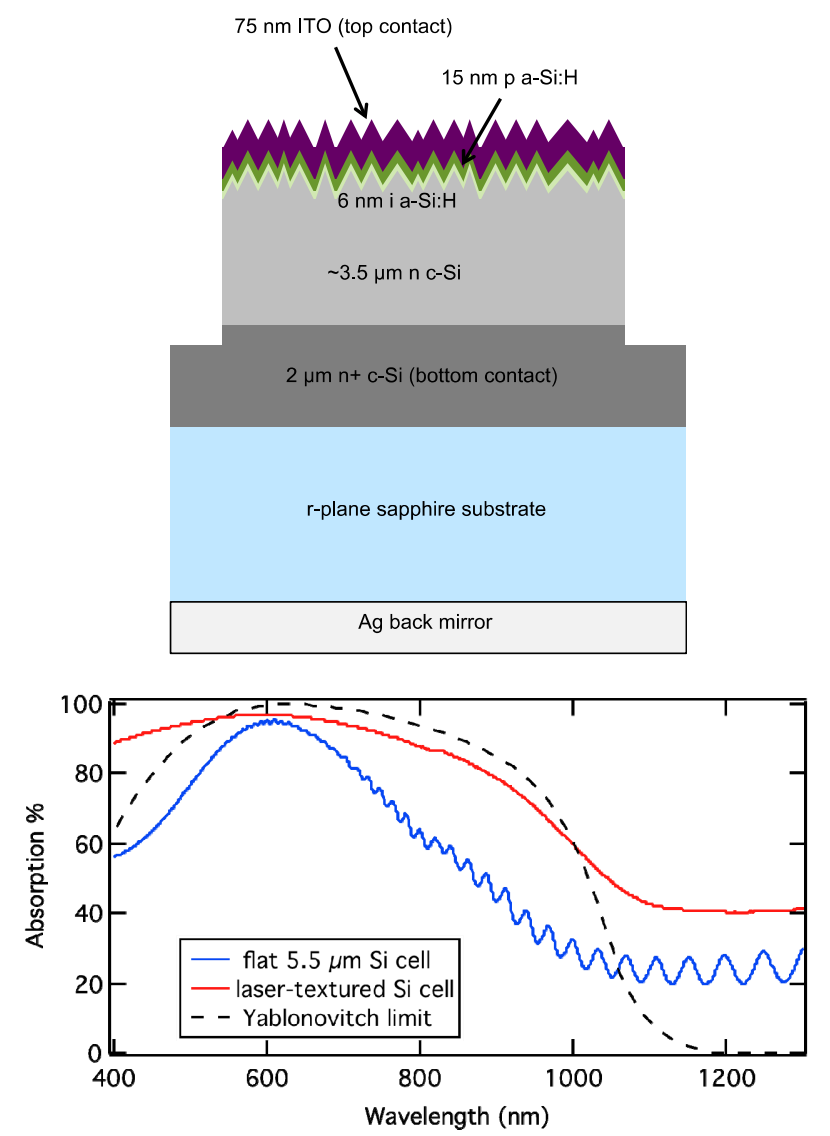

Fig. 3. (a) Schematic cross-section of epitaxial crystalline Si solar cell grown on sapphire substrate, with front side laser texture. (b) Optical absorption of flat and textured epitaxial Si solar cells, as compared to the Yablonovitch Lambertian theory.

The optical absorption was determined, in the same way as with the Si wafer samples (Fig. 3b). Thin-film interference 
fringes are visible for the flat cell, but are absent for the textured cell because of diffuse scattering. Similar to the $\mathrm{Si}$ wafer samples, we see good reduction in reflectivity and also enhancement in light-trapping to nearly the Yablonovitch limit. The decreased reflectivity is most evident in the shortwavelength region $<600 \mathrm{~nm}$, while light-trapping is enhanced for longer wavelengths. We additionally see some parasitic absorption in both flat and textured cells at $>1100 \mathrm{~nm}$ wavelength. This is due to free carrier absorption in the highly-doped bottom contact layer. Light-trapping also enhances the parasitic absorption.

We performed external quantum efficiency (EQE) and current-voltage (I-V) measurements on both flat and textured cells having the same physical thickness. The shape of the $\mathrm{EQE}$ curve for the textured cell is qualitatively similar to its optical absorption (Fig. 4a), except for parasitic free-carrier absorption that doesn't contribute to current. However, the EQE is quite low with very poor collection of photocarriers. This is likely due to a poor Si heterojunction on the lasertextured surface. We are currently investigating methods to remove some thickness of laser-damaged $\mathrm{Si}$, which should improve performance. Notably, despite the overall poor EQE, we still see a small enhancement in the infrared as compared to the flat cell (dashed oval in Fig. 4a).
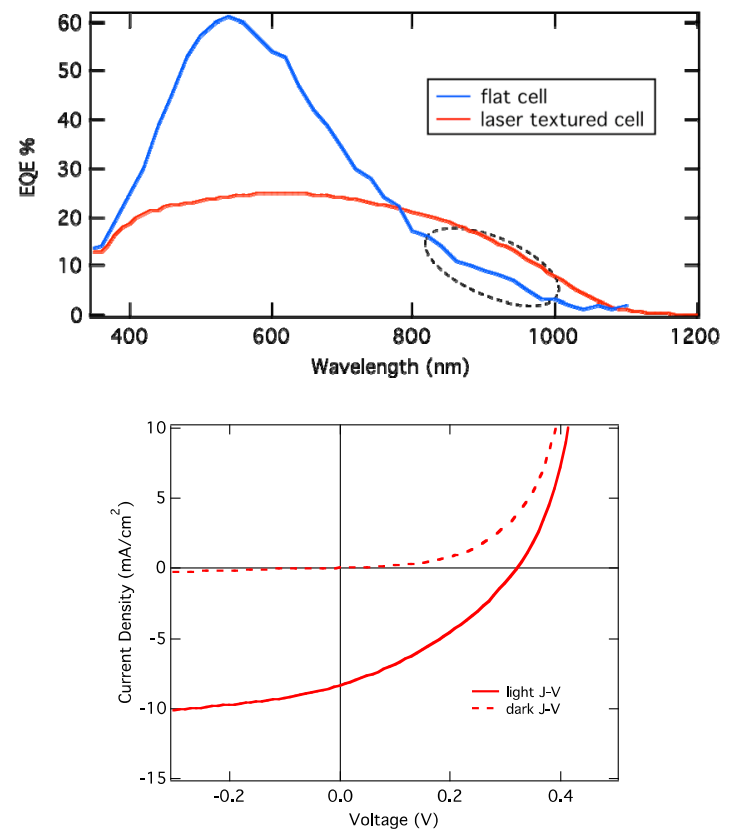

Fig. 4. (a) External quantum efficiency of flat vs. textured epitaxial Si cells. Dashed oval shows infrared QE enhancement of the textured cell. (b) J-V characteristic of textured epitaxial Si cell.

Consistent with the EQE results, the laser-textured cells have low $\mathrm{V}_{\mathrm{OC}} \sim 0.3 \mathrm{~V}$ and $\mathrm{J}_{\mathrm{sc}} \sim 8-12 \mathrm{~mA} / \mathrm{cm}^{2}$. We also see a problem with low shunt resistance in the J-V curve (Fig. 4b), which also points to problems with the junction. We will discuss these issues in subsequent publications and are working on solutions that should give significantly improved cell performance.

\section{CONCLUSION}

Femtosecond laser treatment allows us to create a nearly ideal, randomly-textured surface on Si. Significant reductions in reflectivity and light-trapping absorption enhancements approaching the Yablonovitch limit have been achieved by texturing. We have fabricated working solar cell devices from hetero-epitaxial Si grown on sapphire substrates by HWCVD. The cells have poor EQE, $\mathrm{V}_{\mathrm{OC}} \sim 0.3 \mathrm{~V}$ and $\mathrm{J}_{\mathrm{sc}} \sim 8-12 \mathrm{~mA} / \mathrm{cm}^{2}$. We believe we understand the problem of laser-induced damage, and have methods to significantly improve cell performance in the future. Importantly, these initial results with relatively poor laser-textured cells nonetheless show increased quantum efficiency (vs. un-textured cells) for infrared photons, due to enhanced light-trapping.

\section{ACKNOWLEDGEMENT}

The authors acknowledge K. Bowers, J. Pineau, and T. Fanning of Ampulse Corp. and R. Bauer and L. Roybal of NREL for help in device fabrication. NREL work is supported by the U.S. DOE under Contract DE-AC36-08GO28308. Harvard work is supported by NSF under Contract DMR0934480.

\section{REFERENCES}

[1] R.B. Bergmann et al., "Advances in monocrystalline Si thin film solar cells by layer transfer," Sol. Energy Mater. Sol. Cells 74, 213-218 (2002).

[2] H.M. Branz et al., "Hot-wire chemical vapor deposition of epitaxial film crystal silicon for photovoltaics," Thin Solid Films 519, 4545-4550 (2011).

[3] E. Yablonovitch and G.D. Cody, "Intensity enhancement in textured optical sheets for solar cells," IEEE Transactions on Electron Devices 29, 300-305 (1982).

[4] P. Campbell and M.A. Green, "Light trapping properties of pyramidally textured surfaces," J. Appl. Phys. 62, 243-249 (1987).

[5] K. Van Nieuwenhuysen et al., "Epitaxially grown emitters for thin film silicon solar cells result in 16\% efficiency," Thin Solid Films 518, S80-82 (2010).

[6] R. Younkin et al., "Infrared absorption by conical silicon microstructures made in a variety of background gases using femtosecond-laser pulses," J. Appl. Phys. 93, 2626-2629 (2003).

[7] M.J. Sher et al., "Pulsed-laser hyperdoping and surface texturing for photovoltaics," MRS Bulletin 36, 439-445 (2011).

[8] C. Teplin et al., "Heteroepitaxial film crystal silicon on A12O3: new route to inexpensive crystal silicon photovoltaics," Energy Env. Sci. 4, 3346-3350 (2011). 